\title{
Identifying clinical and educational difficulties of midwives in an Indonesian government hospital maternity ward: Towards improving childbirth care
}

\author{
Yasuko Nagamatsu ${ }^{* 1}$, Rie Tanaka ${ }^{1,2}$, Miyuki Oka ${ }^{1}$, Naoko Maruyamaa ${ }^{1}$, Yenita Agus ${ }^{3}$, Shigeko Horiuchi ${ }^{1}$ \\ ${ }^{1}$ Graduate School of Nursing Science, St. Luke's International University, Tokyo, Japan \\ ${ }^{2}$ Graduate Course of Midwifery, Teikyo University, Tokyo, Japan \\ ${ }^{3}$ Syarif Hidayatullah State Islamic University, Jakarta, Indonesia
}

Received: April 28, 2017

DOI: 10.5430/jnep.v7n11p7
Accepted: May 31, 2017

Online Published: June 6, 2017

\begin{abstract}
Objective: This pilot study aimed to describe the difficulties and educational needs of Indonesian midwives working in a government hospital and thereby propose possible solutions towards improving the quality of childbirth care.

Methods: This study had a qualitative exploratory design. Focus group discussions were conducted with 22 Indonesian midwives working in a government hospital. Data were analyzed using content analysis.

Results: These Indonesian midwives felt they faced difficulties in providing quality care such as "shortage of resources to provide health services", "lack of resources for professional continuing education", "insufficient evidence-based practice", "difficulty in providing care due to cultural background", and "challenges teaching students". Therefore, these difficulties contributed to their uncertainty about the quality of the care they could provide. They desired continuing education to update their knowledge and skills and fill the gap between theory and actual practice. They wanted more in-depth information about "pregnancy", "delivery", "puerperium", "neonates", and "emergencies". These topics reflected the wide range of care needed by the diverse group of Indonesian women who visited government hospital.

Conclusions: Indonesian midwives working in a government hospital had difficulties in providing quality care for women with different needs and backgrounds due to the shortage of midwives, and lack of hospital beds and lack of essential equipment. Even though midwives wanted to learn or update their knowledge and skills to fill the gap between theory they learned in school and the demands of actual practice, the opportunity to have training was very limited.
\end{abstract}

Key Words: Childbirth care, Midwives, Clinical and educational difficulties

\section{INTRODUCTION}

Ending preventable maternal mortality (EPMM) remains one of the world's most critical maternal health issues promoting a health strategy to lower the average global maternal mortality rate (MMR) to fewer than 70 maternal deaths per 100,000 live births by $2030 .{ }^{[1]}$ More than $99 \%$ of maternal deaths occur in low - and middle-income countries, and most of these deaths could be prevented by improving the quality of maternal care. ${ }^{[2]}$

Indonesia is considered a lower-middle-income country with a stable democracy that is undergoing wide-ranging demographic, governmental, and economical transitions that impacts health care provision. ${ }^{[3]}$ Indonesia is an example of a country strongly committed to reducing maternal death by

\footnotetext{
*Correspondence: Yasuko Nagamatsu; Email: sarah-nagamatsu@slcn.ac.jp; Address: Graduate School of Nursing Science, St. Luke’s International University, Tokyo, Japan.
} 
deploying village 60,000 midwives to villages ${ }^{[4]}$ and decentralizing health reforms. ${ }^{[5]}$ As a result, their MMR dropped from 380 deaths per 100,000 live births in 1990 to 126 deaths per 100,000 live births in 2015. ${ }^{[6]}$ Even so, Indonesia did not meet the Millennium Development Goal 5 to reduce MMR to 102 deaths per 100,000 live births by 2015 and has even slowed down in terms of improvement over the last few years. ${ }^{[6]}$ In 2015, 6,400 women died of causes related to pregnancy and childbirth in Indonesia. ${ }^{[7]}$ It is urgent to improve access to quality maternal health services to save pregnant women. Unfortunately, there are barriers, that prevent pregnant women from accessing health facilities, such as an inadequate number of health facilities, few health specialists, poor quality of care, ${ }^{[8]}$ increased distance to health facilities, poor road conditions, ${ }^{[9]}$ and traditional beliefs. ${ }^{[10]}$

In particular, the quality of maternal care resulting from the nation's decentralization is an issue that concerns WHO Indonesia. This is because the 15-fold expansion of pre-service training and lack of consistent standards resulted in issues related to the quality of training and the accreditation of schools. ${ }^{[11]}$ Further, the decentralization of the health system made it more complicated to implement continuing education, which is essential for ensuring the quality of services. ${ }^{[12]}$ Previous reports have identified that the educational needs of nurses and midwives were due mainly to their limited education and preparation received prior to assuming the midwifery role. ${ }^{[8,13]}$ However the Hennessy et al. study was a quantitative study aiming to contribute to the development of midwifery standards and practices, which were nonexistent at the time. ${ }^{[13]}$ There was a paucity of research revealing the clinical and educational needs from the point of view of the midwives working in the clinical area.

Indonesian government hospitals provide care for many people with economic difficulties and who have poor educational backgrounds. Therefore we anticipated that the midwives working in the government hospital might have backgrounds different from the women they serve ${ }^{[10]}$ and therefore have difficulties in fulfilling the wide range of diverse needs. However little was known about the difficulties and educational needs of Indonesian midwives who worked in governmental hospitals. Therefore that remained our research question. We aimed to describe the difficulties and educational needs of Indonesian midwives working in a government hospital and to propose solutions that could provide steps toward the improved quality of midwifery care.

\section{MeTHODS}

\subsection{Study design}

This study had an exploratory design and was intended as a pilot study. We used a qualitative approach because little was known about midwives' educational needs.

\subsection{Study setting and sample}

The research took place in an urban area and within a maternity department in one of the nine government hospitals in Banten Province on the island of Java. This 475-bed hospital handled a wide range of health services, including normal deliveries and emergency care for patients with complications serving the province's urban and traditional cultural groups. There were 81 midwives working on the maternity ward that included six units: delivery, maternity ICU, newborn, NICU, recovery, postpartum and gynecology. The researchers distributed the invitation to participate in the research, which contained information about the purpose of the study to the 81 midwives. A total of $22(27 \%)$ midwives agreed to participate in the research.

\subsection{Data collection}

As there were no previous studies found on Indonesian midwives' perspectives of their work difficulties and learning needs we chose focus group discussions (FGD), which are suitable for collecting a wide range of opinions and are therefore helpful tools in assessing group needs . Krueger ${ }^{[14]}$ suggested, conducting three to four group discussion with five to eight participants each until the researcher collected a range of ideas and was not getting new information. Accordingly, after conducting three focus group discussions with seven or eight participants in each group we reached data saturation.

Data were collected in May 2016 using a self-administrated questionnaire documenting, age, years of experience, main duty, continuing education experience, and motivation for participating in continuing education and content from the focus group discussions. There were two bilingual researchers who facilitated the discussions (one of whom is Japanese Y.N and the other is Indonesian Y.A). The focus groups were conducted in both English and Indonesian. Three Indonesian research assistants obtained verbal consents to type and audiotape the interviews. The facilitators used the following to stimulate the focus group discussions:

(1) Tell us about your satisfaction as a midwife

(2) What type of difficulties are encountered in your midwifery clinical practice

(3) What do you think would solve the difficulties you encountered

(4) Discuss your opportunities for continuing education

(5) Describe your intention of pursuing continuing education

(6) Describe your intention of learning

The first question was general and was used as an ice-breaker 
to generate further discussion and put participants at ease while encouraging them to interact normally with the facilitator. The FGDs lasted approximately 50-60 minutes. The same three Indonesian research assistants then transcribed the interviews verbatim and translated them into English.

\subsection{Data analysis}

Inductive content analysis, ${ }^{[15]}$ was used because there was no prior knowledge pertaining to the difficulties or educational needs of Indonesian midwives working in a government hospital. The following steps were taken to analyze the focus group data: (1) reading (verbatim) the transcribed discussion record; (2) providing explanatory encoding for every sentence or paragraph related to the difficulties and educational needs so that similar sentences or paragraphs shared the same code. (3) generating categories and sub-categories, based on the similarity of each code; (4) discussing the process for generating categories with the six experienced qualitative researchers (YN, RT, MO, NM, YA, and SH.) in order to enhance the trustworthiness of data analysis; and (5) revising the naming or classification of categories based on the discussion. Analysis was conducted in English. The credibility of the results was ensured by triangulating different sources of information, reviewing disconfirming evidence, research reflexivity, member checking, collaboration with participants and Indonesian researchers, and academic advisor's auditing. [16]

\subsection{Ethical considerations}

This study observed all standards for protection of human subjects as set forth by the Declaration of Helsinki. The director of the hospital granted permission to conduct the study. Research assistants obtained informed consent from all informants after they had received oral and written information about the study. The informants were also informed that participation was voluntary and that they could abort their participation in the study at any time without questions being asked or repercussions. Verbal consents were obtained to audiotape the interviews. Anonymity of their responses was assured. Each informant confirmed her participation in writing. Ethical approval for the study was obtained from the Research Ethics Committee of St. Luke's International University, Japan (Approval number:15-0065).

\section{Results}

\subsection{Characteristics of participants}

All the participants were female, with a mean age of 41.5 years and a mean of 18.5 years of midwifery experience. Ten participants mainly worked in the gynecological unit, eight worked in the delivery unit, four worked in the newborn unit, and three worked in the obstetrics unit. Only four midwives

Published by Sciedu Press reported taking part in continuing education activities after graduation from nursing school; however, all expressed a desire to participate in continuing education in the future (see Table 1).

Table 1. Characteristics of participants $(\mathrm{N}=22)$

\begin{tabular}{lll}
\hline Characteristics & & \\
\hline Gender & Female & 22 \\
Age & & $41.5 \pm 10.5$ \\
Experience as midwife & & $18.5 \pm 10.5$ \\
& Delivery unit & 8 \\
Main duty location & Obstetrics unit & 3 \\
(Multiple answers) & Gynecological unit & 10 \\
& Newborn unit & 4 \\
Continuing education & Ever had & 8 \\
experience & Never had & 14 \\
Motivated to participating in & Yes & 22 \\
\hline continuing education & & \\
\hline
\end{tabular}

\subsection{Practice-related difficulties faced by Indonesian midwives}

The difficulties that Indonesian midwives faced during practice were classified into five categories: "shortage of resources to provide health services"; "lack of resources for professional continuing education"; "insufficient evidencebased practice"; "difficulty in providing care due to cultural background" and "challenges teaching students". These categories are explained next in more detail. The following passages are the narrative data. The numbers within parentheses are the identification of the participants. Details are presented in Table 2.

\subsubsection{Shortage of resources to provide health services}

Indonesian midwives faced shortages of resources necessary to provide quality health services. Shortages included basic equipment such as sterile sets, dopplers and gloves. Shortages were due to the insufficient supplies and lengthy repair time. There were also shortages of midwives.

"If we know the patient is HIV positive and there is only one set, we use it for other non-HIV patients first so that the HIV-positive patient can use the set last." "We have to wait for ages for materials to be fixed, such as the Doppler, if it is broken, we wait for ages for it; this can even be a year. Sometimes, we collect money ourselves and fix it using our money." (23)

"Due to the hospital designated as the main referral center [of the province], many patients come in the worst condition, but (maternity) ICU are very limited. Sometimes, the patients are told that the (maternity) ICU are full, but the patients 
still want to be here even though they have to sign the consent that they accept any situation as the impact of not being in the (maternity) ICU ." (31)

"We do have problems with shortage of midwives because we have different rooms [units] for newborns and mothers, so we have to ob- serve two rooms at the same time, but we lack midwives." (13)

"Honestly, we are helped by the students who do their internship. If there are no students, we have lack of helpers to perform the administration; internship help us a lot." (27)

Table 2. Difficulties faced by Indonesian midwives during practice

\begin{tabular}{|c|c|}
\hline Categories & Sub-categories \\
\hline \multirow{4}{*}{$\begin{array}{l}\text { Shortage of resources to provide health } \\
\text { services }\end{array}$} & Shortage of basic supplies (e.g. sterile gloves) \\
\hline & Lengthy time to repair equipment \\
\hline & Not enough beds for patients \\
\hline & Shortage of midwives \\
\hline \multirow{4}{*}{$\begin{array}{l}\text { Lack of resources for professional } \\
\text { continuing education }\end{array}$} & No opportunity for continuous training \\
\hline & No training system available for all midwives \\
\hline & No official certificate to acknowledge competency \\
\hline & No financial support for training \\
\hline \multirow{2}{*}{ Insufficient evidence-based practice } & Lack of up-to-date knowledge and skills \\
\hline & Gap between theory and practice \\
\hline \multirow{3}{*}{$\begin{array}{l}\text { Difficulty in providing care due to cultural } \\
\text { background }\end{array}$} & Delay of care due to poor transportation systems \\
\hline & Difficulty supporting women's type of decision-making \\
\hline & Difficulty educating patients and family members with poor educational background \\
\hline \multirow{2}{*}{ Challenges teaching students } & Lack of equipment and materials for educating students \\
\hline & Lack of current knowledge and skills for adequately teaching students \\
\hline
\end{tabular}

\subsubsection{Lack of resources for professional continuing edu- cation}

Indonesian midwives complained that there were no opportunities to access continuing education. There exists no universally recognized training system for midwives, and there is no official certificate that acknowledges competency. The midwives also referenced a lack of financial support for training.

"But the training is only for the team leader; training is only for leaders, and more than $70 \%$ of us haven't received it. We still need many trainings because it is very costly." "We have training actually, but we don't have an official certificate to legally acknowledge our competency. We had asphyxia training around 10 years ago." (37)

"When we continue our study, we have to pay the cost by ourselves." (24)

\subsubsection{Insufficient evidence-based practice}

Indonesian midwives expressed difficulty in providing evidence-based care to patients. They had no opportunity to learn up-to-date knowledge and skills and perceived a gap between theory and practice.

"There was a gap [theory and practice] in case of a cesarean newborn; accordingly, we had to let the baby nurse, but we were afraid of hypothermia as we already knew that the operation room is very cold. So, we didn't wait until the newborn nursed because of the condition of the mother and baby." (13)

\subsubsection{Difficulty in providing care due to cultural back- ground}

Indonesian midwives had difficulty in providing early, preventative care to patients because of the considerable time required for transport and the complicated process of procuring informed consent. They also expressed difficulty in explaining procedures to patients and family members, given their educational, social, and traditional cultural backgrounds.

"To refer a patient, it is necessary to get approval of the community leader, grandparents, and husband, so it takes time even though the patient's condition gets worst." (23) 
"Educational background of the patients and their family is too low; even if we have explained [something] very clearly, they still don't understand and ask again and again.” (34)

\subsubsection{Challenges teaching students}

Indonesian midwives faced two main challenges in teaching students. They reported lack of equipment and materials necessary for educating students. In addition, they felt that there was a lack of improvement in and updating of knowledge essential for teaching students adequately.

"When there were students who had to undergo examination, they had to provide the equipment by themselves... it's a burden for the teachinglearning process; I wish that the hospital would provide the equipment for the students... so that they don't have to provide it by themselves." (15)

"To improve and refresh knowledge, because trainings are related to coaching students, I am afraid we would give wrong information." (22)

\subsection{Continuing education needs}

The participants were asked about the areas in which they wanted more education. Their responses are presented in Table 3. Responses were classified into 6 categories: "pregnancy", "delivery", "puerperium", "neonate", "emergencies" and "other".

Table 3. Continuing education topics important to Indonesian midwives

\begin{tabular}{|ll|}
\hline \multirow{4}{*}{ Pregnancy } & Antenatal care \\
& Sex education \\
& High-risk pregnancy \\
& Normal delivery care \\
& Delivery without perineal lacerations \\
& Kangaroo mother care \\
& Support for breastfeeding \\
& Family planning \\
& Asphyxia management \\
& Bathing the newborn \\
& High-risk newborn care \\
& Immunization \\
& Neonatal resuscitation \\
& Maternal emergencies \\
Emergencies & Neonatal emergencies \\
& Emergency management \\
& Intra-professional communication skills \\
& Teaching students \\
& Government rules and regulations for midwives \\
& Documentation \\
& Assessment \\
\hline
\end{tabular}

Published by Sciedu Press

\section{Discussion}

The aim of this pilot study was to reveal the difficulties faced by Indonesian midwives while working in a government hospital, therefore FGDs were conducted with 22 Indonesian midwives. The results obtained indicated that these Indonesian midwives faced difficulties such as "shortage of resources to provide health services", "lack of resources for professional continuing education", "insufficient evidencebased practice", "difficulty in providing care due to cultural background" and "challenges teaching students".

\subsection{Uncertain quality of care due to the lack of continu- ing education}

Indonesian midwives working in a government hospital expressed uncertainty about their knowledge and skills in maternal care because of the lack of opportunities for updating their knowledge and skills. The midwives also perceived gaps between theory and real-life practice. They felt these obstacles made it more difficult to provide quality care.

The continuing education subjects that Indonesian midwives wished to learn reflected the wide-ranging care needs of Indonesian women who visited the government hospital for pregnancy, delivery, puerperium, neonate care, emergency care, and other care. Each subject is important for providing quality care to patients in Indonesia. For example, emergency care in midwifery (including resuscitation) directly contributes reducing the MMR and the infant mortality rate (IMR) and is therefore urgently needed. As mentioned by $\mathrm{WHO},{ }^{[17]}$ maintaining competence and confidence in the conduct of necessary clinical skills are critical, particularly those for which the need does not often arise but which are lifesaving when needed, e.g., resuscitation of the adult or newborn. ${ }^{[17-19]}$ There is an urgent need for Indonesian midwives to increase their skill in emergency care. ${ }^{[11]}$ The challenge is how to establish the continuing education system in Indonesia.

Unfortunately, as identified in a previous study, there are few opportunities for midwives to pursue basic continuing professional education in Indonesia. ${ }^{[20]}$ The reasons identified were similar to those reported by. ${ }^{[21]}$ These include lack of manpower, financial problems, insufficient number of lecturers, and an insufficient number of courses in advanced nurse midwifery being taken by personnel. It is not easy to provide continuing education in a country with limited resources or in a geographically dispersed setting such as Indonesia. However, to fulfill its long-term vision, Indonesia must establish a system to monitor the competency of midwives and support their professional development. An Internet-based educational program may be a feasible alternative. ${ }^{[22]}$ 


\subsection{Social support for midwives providing maternal care}

To maximize the quality of care provided by midwives, it is recommended that effective systems be put in place to create a positive practice environment for midwifery services. ${ }^{[22]}$ Social-political support is required for establishing positive practice midwifery care. First, the government, midwifery organizations, and the hospitals must first sanction the knowledge, skills, and procedures that midwives should learn through continuing education; otherwise, midwives cannot apply the new procedure in their practice. Faye ${ }^{[23]}$ reported that satisfaction with salary and management as well as continuing education improves the quality of care. Consequently, it is necessary to develop a midwifery management system that enhances midwives' expertise. Contacts with the midwifery manager, director of hospital, and physicians to communicate the benefits of the introduction of new midwifery are encouraged. To achieve this, collaboration in the development of educational programs would be encouraged.

Second, support for maternal care resources is fundamental. Unfortunately, our study revealed an insufficient number of resources in this government hospital. Another study also found that resource shortages made the performance of basic duties difficult and also damaged the quality of care. ${ }^{[24]}$ The local government, midwifery organizations, hospitals, and other stakeholders need to understand the importance of investing in health care services and supporting resource delivery. ${ }^{[11]}$ Future research should consider using participatory action research involving those groups to move midwifery continuing education forward.

\subsection{Nurturing professional pride and autonomy of mid- wives}

The International Confederation of Midwives ${ }^{[25]}$ has asserted that midwives must empower women/families to speak for themselves on issues affecting the health of women and families within their culture/society and to: (1) actively seek personal, intellectual, and professional growth throughout their midwifery career; (2) integrate this growth into their practice; and (3) participate in the development and implementation of health policies that promote the health of all women and childbearing families an in international code of ethics for midwives. These actions are essential for $\mathrm{In}$ donesian midwives to transcend difficulties that they face in practice. Indonesian midwives working in this government hospital must make efforts to overcome the difficulties by promoting themselves through professional development as well as appealing for support of midwives.

Thomas ${ }^{[26]}$ stated that a central step involved in the journey toward becoming a midwife was women believing in themselves. This helps midwives transcend environmental and or- ganizational constraints and practice "woman-centeredness." Therefore, in the future, it will be necessary to develop a continuing education system for midwives that enables them to feel pride in themselves as midwives, while increasing their functioning as an autonomous profession as well as accumulating new practical knowledge. Effective models for delivering cost-effective continuing education that accommodates Indonesian culture and health belief should be explored.

\subsection{Limitations}

This research was conducted with 22 midwives at a single government hospital. The response rate was less than desirable and therefore introduced potentially biased responses. This was less of a concern as other studies corroborated our findings. Even so future studies should utilize larger samples within various hospitals to compare with the results of our research and to explore variations in resources and continuing education opportunities across types of hospitals and geographical settings. In addition, although the FGD provided data that was in the informants 'voice', the FGS might have also prevented some informants from stating concerns due to peer pressure or social desirability. Therefore it was possible that the Indonesian midwives requests about what they really needed remain unknown; for example no data came forth about working relationships with physicians or other midwives. Our informants had little opportunity to attend continuing education training, and it is therefore possible that they do not fully understand what continuing education can offer. To reveal the real educational needs of Indonesian midwives, further research that includes observation-based research in the clinical area is required.

\section{Conclusion}

Indonesian midwives working in a government hospital perceived their difficulties in providing quality care for women was not only due to women's different needs and backgrounds but also because of the shortage of midwives, availability of beds and lack of necessary equipment. Even though midwives wanted to learn or refresh their knowledge and skill to fill the gap between theory they learnt in the school and practice, the opportunity to have training was limited. They felt their level of clinical knowledge and skill negatively impacted their patient care and ability to adequately education midwifery students.

\section{ACKNOWLEDGEMENTS}

Authors would like to thank to all the respondents for their useful information and cooperation. Also, we never forget Dr. Mardiyanti, Dr. Maulina Handayani and Dr. Puspita Palupi for their faithful support. This study was funded by

ISSN 1925-4040 E-ISSN 1925-4059 
JSPS Asia Africa Platform Program.and Grant-in-Aid for Exploratory Research (23660022). Finally, we would like to thank Dr. Sarah E. Porter for her editorial assistance.

\section{CONFLicts OF INTEREST Disclosure}

The authors declares that there is no conflict of interest.

\section{REFERENCES}

[1] World Health Organization. Strategies towards ending preventable maternal mortality (EPMM). 2015. Available from: http://who.int/reproductivehealth/topics/maternal -perinatal/epmm/en

[2] World Health Organization. Time to respond: a report on the global implementation of Maternal Death Surveillance and Response. 2016. Available from: http: //www.who.int/maternal_child_adolescent/documents/ maternal_death_surveillance_implementation/en/

[3] World Health Organization Regional office for South-East Asia. The Republic of Indonesia Health System Review. World Health Organization. 2017. Available from: http://www. who.int/iris/han $\mathrm{dle} / 10665 / 254716$

[4] Walker D, et al. An economic analysis of midwifery training programmes in South Kalimantan, Indonesia. Bulletin of the World Health Organization. 2002; 80(1): 47-55. http://dx.doi.org/1 $0.1590 / \mathrm{S} 0042-96862002000100009$

[5] Asian Development Band: decentralized health services project in Indonesia [Internet]. Indonesia: Asian Development Bank. 2013. Available from: https://www.adb.org/documents/indonesi a-decentralized-health-services-project

[6] World Health Organization. Trends in maternal mortality: 1990 to 2015: estimates by WHO, UNICEF, UNFPA, World Bank Group and the United Nations Population Division. 2015. Available from: http://www. who.int/reproductivehealth/pub lications/monitoring/maternal-mortality-2015/en/

[7] World Health Organization. World health statistics 2016: monitoring health for the SDGs, sustainable development goals. 2016b. Available from: http://www. who.int/gho/publications/wor ld_health_statistics/2016/en/

[8] World Bank. Accelerating improvement in maternal health: why reform is needed. 2010. Available from: http://documents. worldbank.org/curated/en/43783 $1468266678327 /$ Accelerating-improvement-in-materna 1-health-why-reform-is-needed

[9] Titaley CR, Hunter CL, Heywood P, et al. Why don't some women attend antenatal and postnatal care services?: a qualitative study of community members' perspectives in Garut, Sukabumi and Ciamis districts of West Java Province, Indonesia. BMC Pregnancy Childbirth. 2010; 10: 61. http://doi .org/10.1186/1471-2393-10-61

[10] Agus Y, Horiuchi S. Factors influencing the use of antenatal care in rural West Sumatra, Indonesia. BMC Pregnancy Childbirth. 2012; 12(1): 9. http://doi.org/10.1186/1471-2393-12-9

[11] Joint Committee on Reducing Maternal and Neonatal Mortality in Indonesia; Development, Security, and Cooperation; Policy and Global Affairs; National Research Council; Indonesian Academy of Sciences. Reducing Maternal and Neonatal Mortality in Indonesia: Saving Lives, Saving the Future. Washington (DC): National Academies Press (US); 2013 Dec 26. https ://doi .org/10 . 17226/18437

[12] World Health Organization Regional Office for South-East Asia. WHO Country Cooperation Strategy 2014-2019: Indonesia. World Health Orgaization. 2016. Available from: http://apps.who.int/iris/bitstream/10665/250550/1 /ccs_idn_2014_2019_en.pdf
[13] Hennessy D, Hicks C, Koesno H. The training and development needs of midwives in Indonesia: paper 2 of 3 . Hum Resour Health 2006; 4: 9. http://doi .org/10.1186/1478-4491-4-9

[14] Krueger R, Casey M. Focus groups A Practical Guide for Applied Research (5th ed.). Los Angeles, CA:Sage.2015.

[15] Elo S, Kyngäs $H$. The qualitative content analysis process. Journal of advanced nursing. 2008; 62(1):107-15. http://dx. doi.org/1 $0.1111 / j .1365-2648.2007 .04569 . x$

[16] Creswell JW, Miller DL. Determining validity in qualitative inquiry. Theory Into Practice. 2000;39: 124-130. https://doi .org/10.1 207/s15430421tip3903_2

[17] World Health Organization. Working together for health. The World Health Report 2006. 2006. Available from: http://www. who. int/ whr/2006/whr06_en.pdf?ua=1

[18] Fauveau V. Strategies for reducting maternal mortality. Lancet Global Health. 2006; 368(9544): 1377-86. Available from: http://www.sciencedirect.com/science/article/pii/ S014067360669853X

[19] Koblinsky M, Matthews Z, Hussein J, Mavalankar D, Mridha MK, Anwar I, et al. Going to scale with professional skilled care. The Lancet. 2006; 368 (9544): 1377-86. https ://doi.org/10.1016/ S0140-6736 (06) 69382-3

[20] Hennessy D. Assessment of role, job function and performance of nurse and midwives in community and hospital settings. New Delhi: World Health Organization Regional Office for South-East Asia; 2001. (Report-SEA-NURS-429, INO OSD 001. Restricted publication).

[21] Singchungchai P, Ingkathawornwong T, Kritcharoen S, et al. Management of continuing education of nurse midwives by chief nurses in community hospitals in Southern Thailand. Asian Nursing Research. 2009; 3(4): 147-53. https://doi.org/10.1016/S197 6-1317 (09) 60026-8

[22] World Health Organization. Strengthening Midwifery Toolkit module1. 2011. Available from: http://www who.int/matern al_child_adolescent/documents/strenthening_midwife ry_toolkit/en/

[23] Faye A, Fournier P, Dumont A. Midwives' professional satisfaction and the quality of obstetric care in developing country. Open J Obstet Gynecol. 2017; 7: 95-106. http://doi.org/10.4236/ojog. 201 7.71011

[24] Filby A, McConville F, Portela A. What prevents quality midwifery care? a systematic mapping of barriers in low and middle income countries from the provider perspective. PLoS One. 2016; 11(5): e0153391. http://doi.org/10.1371/journal.pone.0 153391

[25] International confederation of midwives. International code of ethics for midwives; 2014. Available from: http: //internationalmidwives.org/assets/uploads/documen ts/CoreDocuments/CD2008_001\%20V2014\%20ENG\%20Intern ational $\% 20$ Code $\% 20$ of $\% 20$ Ethics $\% 20$ for $\% 20$ Midwives.pdf

[26] Thomas BG. Learning to be a midwife: the need to believe. Evidence Based Midwifery. 2009; 5: 23-28. Available from: https://www.rcm.org.uk/learning-and-career/le arning-and-research/ebm-articles 